\title{
EPIDEMIOLOGICAL ANALYSIS OF LEPTOSPIROSIS IN BULGARIA, 1999-2018
}

\author{
S. Angelova, Y. Mitova, V. Doycheva \\ Department of Epidemiology, Medical University - Sofia, Bulgaria
}

\begin{abstract}
Background: The aim of the study was to characterize the epidemic process of leptospirosis in Bulgaria. Material and methods: Data was collected from the National Centre for Public Health and Analysis official database of infectious diseases for the period 19992018 year. Graphical methods, absolute and relative values were applied when analyzing the data. A regression analysis was used to search for trends in incidence rate and mortality rate over a period of time. Results: For the period 1999-2018, a total of 414 cases of leptospirosis were registered in Bulgaria, 35 of them were lethal. Incidence ranged from 0,10 per 100000 population (2012, 2017 year) to 0,63 per 100000 (1999 year). Using the regression analysis method a model $p=0,03<0,05$ was constructed, which most adequately described the tendency of leptospirosis incidence rate in Bulgaria. Mortality rate was the highest in 2000 $-0,09$ per 100000 and was zero for six years of the survey period. An adequate model was developed $p=0,005<0,05$, which showed the trend of leptospirosis mortality rate. The casefatality rate was high and reached $27,27 \%$ in 2010 . The highest incidence rate of leptospirosis was in the areas of Yambol and Shumen. Leptospirosis in Bulgaria had a seasonal trend. Risk factors for the disease were male gender and age over 55 years. Conclusions: Global environmental changes, including extreme weather conditions, increase the threat of severe epidemics of leptospirosis worldwide. An unfavorable impact on the spread of leptospirosis is the intensive migration of the population and travel-associated cases. Modern control over leptospirosis should be constant, complex and ubiquitous. Therefore, leptospirosis in Bulgaria should not be underestimated.
\end{abstract}

Key words: leptospirosis, cases, incidence rate, mortality rate, case-fatality rate

Corresponding author: S. Angelova, Department of Epidemiology, Medical University, Sofia, SBALAG "Maychin dom", floor 6, room 665, 2, Zdrave Street, Bg-1431 Sofia, tel: 029523844 , E-mail: a.svetla.angelova@abv.bg

RECEIVED: 13 September 2019, ACCEPTED: 5 October 2019

\section{INTRODUCTION}

eptospirosis, a disease caused by pathogenic spirochetes belonging to the Leptospira genus, represents a worldwide public health problem affecting both industrialized and developing countries. Annually, approximately 500000 severe cases occur worldwide, with a mortality rate of $5-20 \%$ [1].
Humans are infected through direct contact with infected animals, or through contact with water or soil that has been contaminated by urine of infected animals; occasionally, through drinking of water and ingestion of food contaminated with urine of infected animals, often rats; also through inhalation of droplet aerosols of contaminated fluids. Disease transmission is strongly driven by environmental factors 
including heavy rainfall, flooding, natural disasters, population growth, urbanization, and poor sanitation and hygiene [2, 3, 4, 5]. In addition, infection risk depends on individual behaviour (e.g. swimming in fresh water, working outdoors), and contact with animals including livestock, rodents, pets and wildlife $[2,4]$. Risk factors for infections and drivers of outbreaks depend on interactions between humans, animals, and the environment, and vary significantly between locations based on environmental, cultural, and socio-demographic factors [4].

\section{MATERIALS AND METHODS}

The aim of the study was to characterize the epidemic process of leptospirosis in Bulgaria. Data was collected from the National Centre for Public Health and Analysis official database of infectious diseases for the period 1999-2018 year.

Graphical methods, absolute and relative (dynamic and intensive) values were applied when analyzing the data. A regression analysis was used to search for trends in incidence rate and mortality rate over a period of time. The incidence trend was calculated according to the following formula: incidence rate per $100000=27,873-0,14{ }^{*}$ Year, the year is an independent variable and incidence rate is dependent. To find the mortality rate trend, the following equation was used: Mortality rate per $100000=5,086-0,003$ * Year, with the year being an independent variable and mortality rate - a dependent one.

\section{RESULTS}

For the period 1999-2018, a total of 414 cases of leptospirosis were registered in Bulgaria, 35 of them were lethal. Incidence rate ranged from 0,10 per 100 000 population $(2012,2017)$ to 0,63 per 100000 (1999 year). Using the regression analysis method a model $p=0,03<0,05$ was constructed, which most adequately described the tendency of leptospirosis incidence rate in Bulgaria. Mortality rate was the highest in 2000-0,09 per 100000 and was zero for six years of the survey period (Table 1, Fig. 1). An adequate model was developed $p=0,005<0,05$, which showed the trend of leptospirosis mortality rate. The case-fatality rate was high and reached $27,27 \%$ in 2010 (Table 1, Fig. 2).

The age structure of leptospirosis incidence rate, for the period 2009-2018, showed that approximately $50 \%(71 / 144)$ of the registered cases were of people over 55 years of age. There were no cases of leptospirosis in children up to 9 years of age. In the age groups of $10-14$ and $15-19$, single cases of the disease were recorded (Tabl. 2). Table 3 shows that the highest leptospirosis incidence rate was reached in 2014, in the 55-59 age group (1,96 per 100 000).

The territorial structure of the leptospirosis incidence rate in Bulgaria is presented in Table 4. There were no registered cases of leptospirosis in seven out of the 28 regions in Bulgaria (Kardzhali, Kyustendil, Pernik, Razgrad, Silistra, Smolyan and Haskovo). Three cases of leptospirosis were reported in three areas (Vidin, Pazardzhik and Targovishte). The highest incidence rate of leptospirosis was recorded in 2014 in the following areas: Gabrovo (5,92/100 000), Dobrich (5,41/100 000), Lovech (4,43/100 000) and Yambol, 15/100 000). In 2018, in the region of Gabrovo the leptospirosis incidence rate $(4,53 / 100$ $000)$ was significantly higher than the average for the country $(0,21 / 100000)$. The leptospirosis incidence rate in Yambol area was several times higher than the average for the country during the survey period, with the exception of 2017 when zero incidence rate was recorded. Shumen region also had an incidence rate above the national average for eight years during the period of 2009-2018.

Leptospirosis in Bulgaria had a seasonal pattern, most cases of which were recorded between June and September (maximum frequency in July and August) (Fig. 3). A risk factor for leptospirosis was the male gender (male/female ratio - 4/1) (Fig. 4).

According to epidemiological studies of the Regional Inspectorates for the Protection and Control of Public Health (RIPCPH), the factors contributing to the spread of leptospirosis were predominantly rodent contaminated food and objects, livestock breeding, less frequent bathing in natural waterbodies [6].

\section{DISCUSSION}

In Bulgaria, the official registration of human leptospirosis dated back to 1952. A trend to decrease the incidence of leptospirosis in our country has been observed [7, 8]. In Europe, the incidence rate of leptospirosis decreased during the second half of the last century [9].

In 2017, 931 confirmed leptospirosis cases were reported in 25 European countries [10]. With an overall incidence rate of $0,20 / 100000$ population, leptospirosis remained a rare disease in EU countries. The highest leptospirosis notification rates were observed in Slovenia (1,16/100 000 population), Portugal $(1,13 / 100000$ population) and Austria (0,78/100 000 population) [10]. The results of our study show that Bulgaria is among the countries with the lowest leptospirosis incidence rate in the EU $(0,10 / 100000)$. 


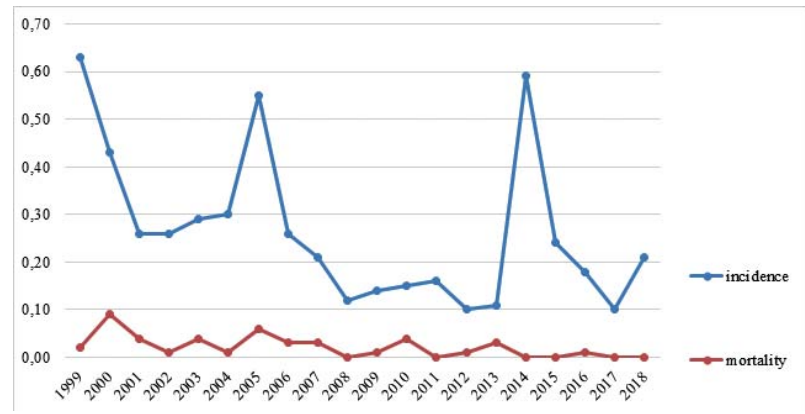

Fig. 1. Evolution of leptospirosis incidence and mortality rate in Bulgaria (cases/100 000), 1999-2018

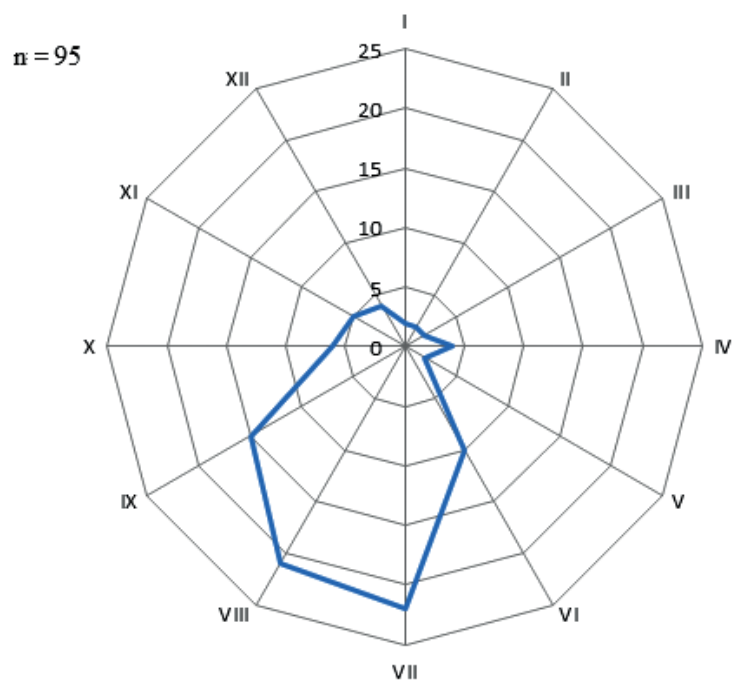

Fig. 3. Seasonal distribution of leptospirosis cases, Bulgaria, Fig. 4. Distribution by sex of patients with leptospirosis, Bulgaria, 2014-2018

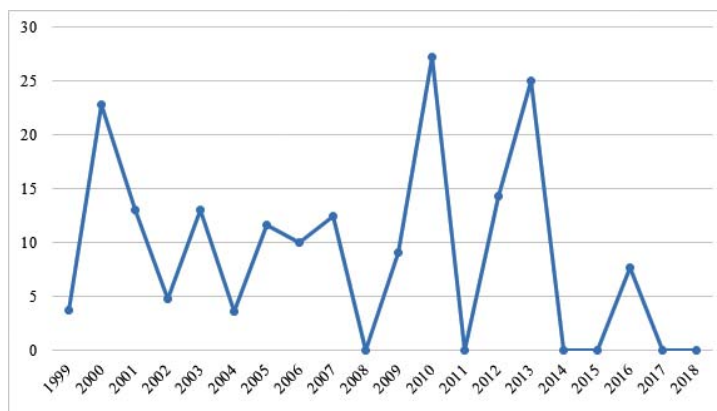

Fig. 2. Evolution of leptospirosis case-fatality rate (per 100) of

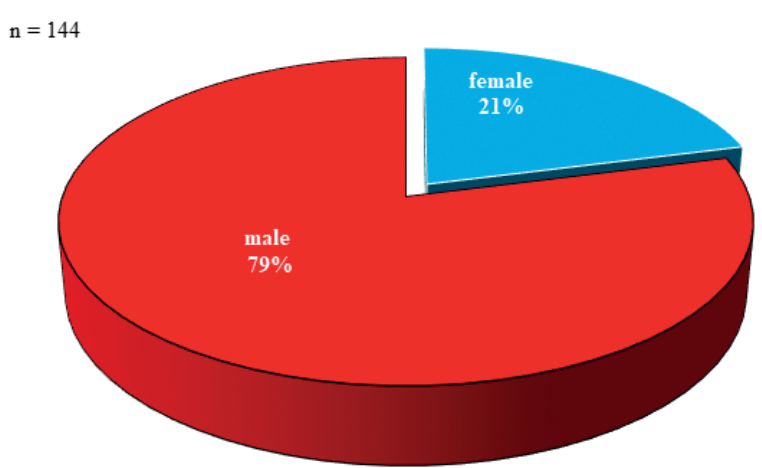

2009-2018 leptospirosis in Bulgaria, 1999-2018

Table 1. Number of Cases, Number of Deaths, Incidence Rate, Mortality Rate (per 100000 population), Case Fatality Rate (per 100) of Leptospirosis, Bulgaria, 1999-2018

\begin{tabular}{|c|c|c|c|c|c|}
\hline Year & Cases $(\mathbf{n})$ & Incidence Cases/100,000 & Deaths $(\mathbf{n})$ & Mortality Rate Cases/100 000 & Case Fathality Rate per 100 \\
\hline 1999 & 53 & 0,63 & 2 & 0,02 & 3,77 \\
\hline 2000 & 35 & 0,43 & 8 & 0,09 & 22,86 \\
\hline 2001 & 22 & 0,26 & 3 & 0,04 & 13,64 \\
\hline 2002 & 21 & 0,26 & 1 & 0,01 & 4,76 \\
\hline 2003 & 23 & 0,29 & 3 & 0,04 & 3,04 \\
\hline 2004 & 28 & 0,30 & 1 & 0,01 & 11,63 \\
\hline 2005 & 43 & 0,55 & 5 & 0,06 & 10,00 \\
\hline 2006 & 20 & 0,26 & 2 & 0,03 & 12,50 \\
\hline 2007 & 16 & 0,21 & 2 & 0,03 & 0,00 \\
\hline 2008 & 9 & 0,12 & 0 & 0,00 & 9,09 \\
\hline 2009 & 11 & 0,14 & 1 & 0,01 & 27,27 \\
\hline 2010 & 11 & 0,15 & 3 & 0,04 & 0,00 \\
\hline 2011 & 12 & 0,16 & 0 & 0,00 & 14,29 \\
\hline 2012 & 7 & 0,10 & 1 & 0,01 & 0,00 \\
\hline 2013 & 8 & 0,11 & 2 & 0,03 & 0,00 \\
\hline 2014 & 43 & 0,59 & 0 & 0,00 & 7,69 \\
\hline 2015 & 17 & 0,24 & 0 & 0,00 & 0,00 \\
\hline 2016 & 13 & 0,18 & 1 & 0,01 & 0,00 \\
\hline 2017 & 7 & 0,10 & 0 & 0,00 & \\
\hline 2018 & 15 & 0,21 & 0 & 0,00 & \\
\hline
\end{tabular}


Table 2. Distribution of Leptospirosis (Number of Cases) by age groups, Bulgaria,2009-2018

\begin{tabular}{|c|c|c|c|c|c|c|c|c|c|c|c|c|c|c|c|}
\hline \multirow{2}{*}{ Year } & \multicolumn{10}{|c|}{ Age groups/Number of Cases } \\
\cline { 2 - 8 } & $\mathbf{0}$ & $\mathbf{1 - 4}$ & $\mathbf{5 - 9}$ & $\mathbf{1 0 - 1 4}$ & $\mathbf{1 5 - 1 9}$ & $\mathbf{2 0 - 2 4}$ & $\mathbf{2 5 - 2 9}$ & $\mathbf{3 0 - 3 4}$ & $\mathbf{3 5 - 3 9}$ & $\mathbf{4 0 - 4 4}$ & $\mathbf{4 5 - 4 9}$ & $\mathbf{5 0 - 5 4}$ & $\mathbf{5 5 - 5 9}$ & $\mathbf{6 0 - 6 4}$ & $\mathbf{6 5 +}$ \\
\hline 2009 & 0 & 0 & 0 & 0 & 0 & 0 & 1 & 0 & 0 & 1 & 0 & 3 & 1 & 1 & 4 \\
\hline 2010 & 0 & 0 & 0 & 0 & 0 & 1 & 0 & 2 & 0 & 2 & 3 & 1 & 0 & 1 & 1 \\
\hline 2011 & 0 & 0 & 0 & 0 & 1 & 1 & 0 & 2 & 0 & 2 & 0 & 1 & 0 & 2 & 3 \\
\hline 2012 & 0 & 0 & 0 & 0 & 0 & 0 & 0 & 1 & 1 & 2 & 0 & 0 & 1 & 2 & 0 \\
\hline 2013 & 0 & 0 & 0 & 0 & 0 & 0 & 2 & 0 & 0 & 1 & 1 & 3 & 0 & 0 & 1 \\
\hline 2014 & 0 & 0 & 0 & 0 & 0 & 2 & 3 & 2 & 2 & 4 & 2 & 5 & 10 & 6 & 7 \\
\hline 2015 & 0 & 0 & 0 & 0 & 0 & 2 & 1 & 0 & 2 & 0 & 1 & 1 & 3 & 2 & 5 \\
\hline 2016 & 0 & 0 & 0 & 0 & 0 & 0 & 0 & 0 & 0 & 0 & 1 & 3 & 3 & 1 & 5 \\
\hline 2017 & 0 & 0 & 0 & 0 & 0 & 0 & 0 & 0 & 1 & 0 & 1 & 0 & 1 & 1 & 3 \\
\hline 2018 & 0 & 0 & 0 & 1 & 0 & 0 & 0 & 0 & 3 & 0 & 2 & 2 & 2 & 2 & 3 \\
\hline
\end{tabular}

Table 3. Leptospirosis Incidence rate by age group (Cases/100 000), Bulgaria, 2009-2018.

\begin{tabular}{|c|c|c|c|c|c|c|c|c|c|c|c|c|c|c|c|}
\hline \multirow{2}{*}{ Year } & \multicolumn{15}{|c|}{ Age group, years/ Incidence rate } \\
\hline & 0 & $1-4$ & $5-9$ & $10-14$ & $15-19$ & $20-24$ & $25-29$ & $30-34$ & $35-39$ & $40-44$ & $45-49$ & 50-54 & $55-59$ & $60-64$ & $65+$ \\
\hline 2009 & 0,00 & 0,00 & 0,00 & 0,00 & 0,00 & 0,00 & 0,20 & 0,00 & 0,00 & 0,20 & 0,00 & 0,60 & 0,20 & 0,20 & 0,30 \\
\hline 2010 & 0,00 & 0,00 & 0,00 & 0,00 & 0,00 & 0,20 & 0,00 & 0,30 & 0,00 & 0,40 & 0,60 & 0,20 & 0,00 & 0,20 & 0,10 \\
\hline 2011 & 0,00 & 0,00 & 0,00 & 0,00 & 0,28 & 0,20 & 0,00 & & 0,00 & & 0,00 & 0,20 & 0,00 & 0,38 & 0,20 \\
\hline 2012 & 0,00 & 0,00 & 0,00 & 0,00 & 0,00 & 0,00 & 0,00 & 0,19 & & & 0,00 & 0,00 & & 0,38 & 0,00 \\
\hline 2013 & 0,00 & 0,00 & 0,00 & 0,00 & 0,00 & 0,00 & 0,41 & 0,00 & 0,00 & $0,1 \mathrm{~s}$ & 0,21 & 0,60 & 0,00 & 0,00 & 0,07 \\
\hline 2014 & 0,00 & 0,00 & 0,00 & 0,00 & 0,00 & 0,46 & 0,61 & 0,40 & 0,36 & 0,76 & 0,41 & 1,00 & 1,96 & 1,16 & 0,49 \\
\hline 2015 & 0,00 & 0,00 & 0,00 & 0,00 & 0,00 & 0,49 & 0,21 & 0,00 & 0,37 & 0,00 & 0,20 & 0,20 & 0,60 & 0,39 & 0,35 \\
\hline 2016 & 0,00 & 0,00 & 0,00 & 0,00 & 0,00 & 0,00 & 0,00 & 0,00 & 0,00 & 0,00 & 0,20 & 0,62 & 0,60 & 0,20 & 0,34 \\
\hline 2017 & 0,00 & 0,00 & 0,00 & 0,00 & 0,00 & 0,00 & 0,00 & 0,00 & 0,19 & 0,00 & 0,20 & 0,00 & 0,20 & 0,20 & 0,20 \\
\hline 2018 & 0,00 & 0,00 & 0,00 & 0,31 & 0,00 & 0,00 & 0,00 & 0,00 & 0,60 & 0,00 & 0,39 & 0,43 & 0,41 & 0,41 & 0,20 \\
\hline
\end{tabular}

Table 4. Leptospirosis Incidence in Region, (cases/100 000 population), Bulgaria, 2009-2018

\begin{tabular}{|l|l|l|l|l|l|l|l|l|l|l|}
\hline Region / year & $\mathbf{2 0 0 9}$ & $\mathbf{2 0 1 0}$ & $\mathbf{2 0 1 1}$ & $\mathbf{2 0 1 2}$ & $\mathbf{2 0 1 3}$ & $\mathbf{2 0 1 4}$ & $\mathbf{2 0 1 5}$ & $\mathbf{2 0 1 6}$ & $\mathbf{2 0 1 7}$ & $\mathbf{2 0 1 8}$ \\
\hline Blagoevgrad & 0,61 & 0,00 & 0,00 & 0,00 & 0,00 & 0,00 & 0,32 & 0,00 & 0,00 & 0,00 \\
\hline Burgas & 0,71 & 0,00 & 0,47 & 0,00 & 0,00 & 0,00 & 0,00 & 0,48 & 0,24 & 0,24 \\
\hline Varna & 0,00 & 0,21 & 0,00 & 0,00 & 0,42 & 0,00 & 0,21 & 0,21 & 0,00 & 0,21 \\
\hline Veliko Turnovo & 0,00 & 0,00 & 0,00 & 0,00 & 0,00 & 0,00 & 0,40 & 0,41 & 0,00 & 0,00 \\
\hline Vidin & 0,00 & 0,00 & 0,00 & 0,00 & 0,00 & 0,00 & 0,00 & 0,00 & 0,00 & 1,15 \\
\hline Vratsa & 0,00 & 0,51 & 0,52 & 0,00 & 0,00 & 4,48 & 0,00 & 0,58 & 0,00 & 0,00 \\
\hline Gabrovo & 0,00 & 0,00 & 0,00 & 0,00 & 0,00 & 5,92 & 0,00 & 1,75 & 0,00 & 4,53 \\
\hline Dobrich & 0,00 & 0,00 & 0,00 & 0,00 & 0,00 & 5,41 & 0,55 & 0,00 & 0,00 & 0,00 \\
\hline Kardzhali & 0,00 & 0,00 & 0,00 & 0,00 & 0,00 & 0,00 & 0,00 & 0,00 & 0,00 & 0,00 \\
\hline Kyustendil & 0,00 & 0,00 & 0,00 & 0,00 & 0,00 & 0,00 & 0,00 & 0,00 & 0,00 & 0,00 \\
\hline Lovech & 0,00 & 0,00 & 0,68 & 0,00 & 0,73 & 4,43 & 1,50 & 0,00 & 0,00 & 1,58 \\
\hline Montana & 0,63 & 0,00 & 0,65 & 0,00 & 0,70 & 0,71 & 0,00 & 0,73 & 1,49 & 0,00 \\
\hline Pazardzhik & 0,00 & 0,00 & 0,00 & 0,00 & 0,00 & 0,00 & 0,00 & 0,38 & 0,00 & 0,00 \\
\hline Pernik & 0,00 & 0,00 & 0,00 & 0,00 & 0,00 & 0,00 & 0,00 & 0,00 & 0,00 & 0,00 \\
\hline
\end{tabular}


Continio tabl. 4

\begin{tabular}{|l|l|l|l|l|l|l|l|l|l|l|}
\hline Pleven & 0,00 & 0,69 & 0,00 & 0,75 & 0,00 & 0,00 & 0,00 & 0,00 & 0,40 & 0,41 \\
\hline Plovdiv & 0,00 & 0,00 & 0,14 & 0,00 & 0,00 & 0,29 & 0,30 & 0,00 & 0,15 & 0,15 \\
\hline Razgrad & 0,00 & 0,00 & 0,00 & 0,00 & 0,00 & 0,00 & 0,00 & 0,00 & 0,00 & 0,00 \\
\hline Ruse & 0,00 & 0,00 & 0,00 & 0,00 & 0,00 & 0,44 & 0,00 & 0,00 & 0,00 & 0,45 \\
\hline Silistra & 0,00 & 0,00 & 0,00 & 0,00 & 0,00 & 0,00 & 0,00 & 0,00 & 0,00 & 0,00 \\
\hline Sliven & 0,48 & 0,00 & 0,00 & 0,00 & 1,02 & 0,00 & 0,00 & 0,00 & 0,00 & 0,00 \\
\hline Smolyan & 0,00 & 0,00 & 0,00 & 0,00 & 0,00 & 0,00 & 0,00 & 0,00 & 0,00 & 0,00 \\
\hline Sofia-capital & 0,00 & 0,08 & 0,00 & 0,15 & 0,08 & 0,08 & 0,15 & 0,08 & 0,08 & 0,00 \\
\hline Sofia-region & 0,39 & 0,40 & 0,00 & 0,00 & 0,00 & 0,00 & 0,00 & 0,00 & 0,00 & 0,00 \\
\hline Stara Zaora & 0,00 & 0,00 & 0,00 & 0,00 & 0,00 & 0,30 & 0,31 & 0,00 & 0,00 & 0,00 \\
\hline Targovishte & 0,76 & 0,00 & 0,00 & 0,00 & 0,00 & 0,00 & 0,00 & 0,00 & 0,00 & 0,00 \\
\hline Haskovo & 0,00 & 0,00 & 0,00 & 0,00 & 0,00 & 0,00 & 0,00 & 0,00 & 0,00 & 0,00 \\
\hline Shumen & 0,51 & 1,55 & 2,60 & 0,00 & 0,00 & 1,12 & 1,13 & 0,57 & 0,57 & 0,58 \\
\hline Yambol & 0,71 & 1,44 & 0,74 & 2,31 & 0,78 & 3,15 & 3,18 & 1,62 & 0,00 & 0,83 \\
\hline Bulgaria & 0,10 & 0,15 & 0,16 & 0,10 & 0,11 & 0,59 & 0,24 & 0,18 & 0,10 & 0,21 \\
\hline
\end{tabular}

Indeed, most risk factors associated with leptospirosis endemicity (tropical climate, flooding, poor sanitation) are not traditionally encountered in EU countries [3]. This infection occurs most commonly in the tropics because the climate as well as the sometimespoor hygienic conditions favor the pathogen's survival and distribution [11]. Cyclical changes in the incidence rate of leptospirosis occurring over several years were also affected by adverse weather conditions [12]. In Bulgaria, although there are no specific studies, years of heavy rainfall and floods coincide with the highest levels of leptospirosis incidence rate. During the period 1999-2018, three peaks of leptospirosis were registered in Bulgaria (1999, 2005, and 2014) (Fig. 2). In 1999 torrential rains affected $1 / 3$ of the country, in $200575 \%$ of Bulgarian territory was flooded [13] and in 2014 eleven districts were affected by floods.

The results of a survey for the period 2010-2011 show that leptospirosis incidence rate in Bulgaria was caused by 5 serovars. The leading serogroup was that of Leptospira icterohaemorrhagiae demonstrated in $14 / 28(50 \%)$ of the study patients. The rate of infections caused by this serogroup showed a tendency to decrease compared to previous studies $[14,15]$. The second most frequent serogroup was the Leptospira Sejroe, confirmed by $21,43 \%$ of the patients $(6 / 28)$. There was a significant increase in the relative share of this serogroup compared to previous studies $(8,93 \%)[8,14,15,16]$. In all nine leptospirosis patients in 2008, Leptospira icterohaemorrhagiae was serologically diagnosed
[6]. Some serovars are generally associated with particular animals (e.g., Icterohaemorrhagiae and Copenhageni with rats, Grippotyphosa with voles, Hardjo with cattle, Canicola with dogs, and Pomona with pigs) but may occur in other animals as well [11]. Despite the limited data in our study, as a risk factor for spreading leptospirosis, an increase in the population of rodents in the inhabited areas can be indicated.

\section{CONCLUSION}

For the period 1999-2018, the incidence and mortality rates of leptospirosis in Bulgaria tended to decrease. Despite the limited prevalence of leptospirosis, the case-fatality rate was high. Global environmental changes, including extreme weather conditions, increase the threat of severe epidemics of leptospirosis worldwide. An unfavorable impact on the spread of leptospirosis is the intensive migration of the population and travel-associated cases. Modern control over leptospirosis should be constant, complex and ubiquitous. Therefore, leptospirosis in Bulgaria should not be underestimated.

Disclosure summary: The authors have nothing to disclose.

\section{REFERENCES}

1. Levett PN. Leptospirosis. Clinical Microbiology Reviews 2001;14(2):296-326. 
2. Costa F, Hagan JE, Calcagno J, et al. Global Morbidity and Mortality of Leptospirosis: A Systematic Review. PLoS Negl Trop Dis. 2015;9: e0003898. pmid:26379143 View Article PubMed/NCBI Google Scholar

3. Lau CL, Smythe LD, Craig SB, Weinstein P. Climate Change, Flooding, Urbanisation and Leptospirosis: Fuelling the Fire? Trans R Soc Trop Med Hyg. 2010;104: 631638. pmid:20813388 View Article PubMed/NCBI Google Scholar

4. Mwachui MA, Crump L, Hartskeerl R et al. Environmental and Behavioural Determinants of Leptospirosis Transmission: A Systematic Review. PLoS Negl Trop Dis. 2015;9: e0003843. pmid:26379035 View Article PubMed/NCBI Google Scholar

5. Meslin F, Leptospirosis: Heymann David L. Control of Communicable Diseases Manual (CCDM), the 18th revision 2008, 334-337.

6. National Center of Infectious and Parasitic Diseases. Analyzes of infectious diseases. (in Bulgarian).www.ncipd.org.

7. Doycheva V., Dimitrova T., Mitova Y. Epidemiological characteristics of leptospirosis in Bulgaria. Bulgarian Medical Journal, VI, 2012, № 3, 70-73.

8. Gancheva E, Manev Ch., Halacheva M. Epidemiological and epizootiological analysis of leptospirosis, 1986-1990. Bulletin of the National Center for infectious and Parasitic Diseases, 1990; 6:57-59.
9. Socolovschi C, Angelakis E, Renvoisé A et al. Strikes, flooding, rats, and leptospirosis in Marseille, France. International Journal of Infectious Diseases 2011;15:e710-5.

10. Disease data from ECDC Surveillance Atlas, Available from: htts://ecdc.europa.eu/en/surveillance-and-disease-data/atlas.

11. Peter Speelman, Rudy Hartskeerl, Leptospiroses, Harrison's Infectious Diseases, Derived from Harrison's Principles of Internal Medicine, 17th Edition, The McGraw-Hill Companies ("McGraw Hill"), 2010: 660-665

12. WHO, WEK, Leptospirosis: an emerging public health problem, 86, 2011, 6: 45-46.

13. Romanova H, Radeva N, Marinova I et al Floods - most frequently disaster. Causes, consequences,organizational measures., Knowledge of scintists - Varna 2012;(2),18,65-70.

14. Taseva E, Hristova I, Gladnishka T, Trifonova, Ivanova V. Leptospirosis in humans in Bulgaria - a new challenge for medicine or problem solved. Retrospective analysis of infection for 2010-2011. Scince Infectology and Parasitology, 2012 (1):22-29

15. Taseva E, Hristova I, Gladnishka T et al. Clinical and serological aspects and prognostic factors of leptospirosis in humans in Bulgaria, a retrospective study for the period 2006-2009, Infectology, 2010, 47, 2:36-43 (in Bulgarian).

16. Taseva E, Hristova I, Gladnishka T. Epidemiological, clinical and serological evidence of leptospirosis in human in Bulgarian for 2002-2005, Jurnal Infectology, 2007,44,2:26-31 (in Bulgarian). 